\title{
Universiteit
}

Leiden

The Netherlands

\section{The synthesis of cyclophellitol-aziridine and its configurational and functional isomers}

Jiang, J.; Artola Perez de Azanza, M.E.; Beenakker, T.J.M.; Schröder, S.P.; Petracca, R.; Boer, C. de; ... ; Overkleeft, H.S.

\section{Citation}

Jiang, J., Artola Perez de Azanza, M. E., Beenakker, T. J. M., Schröder, S. P., Petracca, R., Boer, C. de, ... Overkleeft, H. S. (2016). The synthesis of cyclophellitol-aziridine and its configurational and functional isomers. European Journal Of Organic Chemistry, 2016(22), 3671-3678. doi:10.1002/ejoc.201600472

Version: $\quad$ Publisher's Version

License: $\quad$ Licensed under Article 25fa Copyright Act/Law (Amendment Taverne)

Downloaded from: https://hdl.handle.net/1887/3199777

Note: To cite this publication please use the final published version (if applicable). 


\title{
Aziridine Synthesis
}

\section{The Synthesis of Cyclophellitol-Aziridine and Its Configurational and Functional Isomers}

\author{
Jianbing Jiang, ${ }^{[a]}$ Marta Artola, ${ }^{[a]}$ Thomas J. M. Beenakker, ${ }^{[a]}$ Sybrin P. Schröder, ${ }^{[a]}$ \\ Rita Petracca, ${ }^{[\mathrm{a}]}$ Casper de Boer, ${ }^{[\mathrm{a}]}$ Johannes M. F. G. Aerts, ${ }^{[\mathrm{b}]}{ }^{\mathrm{Gij}}$ sbert A. van der Marel, ${ }^{[\mathrm{a}]}$ \\ Jeroen D. C. Codée, ${ }^{[a]}$ and Herman S. Overkleeft*[a]
}

Abstract: Cyclophellitol and cyclophellitol-aziridine are potent, mechanism-based and irreversible retaining $\beta$-glucosidase inhibitors. We have become interested in these configurational $\beta$ glucoside analogues as they proved to be a highly suitable starting point for the development of activity-based glycosidase probes. In this review, we provide an overview of the cyclophellitol-aziridine synthesis reported in the literature. Two con- ceptually different strategies for the introduction of the aziridine moiety have been used, one starting from the inverted epoxide and one with intramolecular iodocyclisation from a homo-allylic alcohol as the key step. These are discussed in this microreview, and their application in the synthesis of configurational and functional cyclophellitol-aziridine isomers is presented as well.

\section{Introduction}

The natural product cyclophellitol ${ }^{[1]}(\mathbf{1}$, Figure 1, A) and its synthetic analogue, cyclophellitol-aziridine $(\mathbf{2})^{[2]}$ are potent, mechanism-based and irreversible retaining $\beta$-glucosidase inhibitors. Retaining $\beta$-glucosidases employ a Koshland double displacement mechanism ${ }^{[3]}$ in substrate hydrolysis (Figure 1, B), and this process proceeds through a covalent enzyme-glucoside intermediate. Both cyclophellitol (1) and cyclophellitol-aziridine (2) capitalize on this mechanism. They are configurational $\beta$-glucopyranose analogues, and outperform the structurally related (and much wider studied) conduritol B epoxide (3, CBE - lacking the C8 methylene compared to $\mathbf{1}$ in potency and selectivity as retaining $\beta$-glucosidase inhibitors). ${ }^{[4]}$ Compounds $\mathbf{1}$ and $\mathbf{2}$ adopt a ${ }^{4} \mathrm{H}_{3}$ half chair conformation, thereby emulating the oxocarbenium ion-like transition state. ${ }^{[5]}$ This oxocarbenium ion is

[a] Department of Bio-organic Synthesis, Leiden Institute of Chemistry, Leiden University,

Einsteinweg 55, 2333 CC Leiden, The Netherlands

E-mail: h.s.overkleeft@lic.leidenuniv.nl

http://biosyn.lic.leidenuniv.n/

[b] Department of Medical Biochemistry, Leiden Institute of Chemistry, Leiden University,

Einsteinweg 55, 2333 CC Leiden, The Netherlands trapped to yield the glycosyl-enzyme intermediate and the acylal linkage is then hydrolyzed to release $\beta$-glucose with double inversion - thus net retention - of the anomeric carbon configuration. ${ }^{[6]}$ Due to their preferred conformation, cyclitols 1 and $\mathbf{2}$ fit well in the retaining $\beta$-glucosidase active site and present the epoxide (see $\mathbf{1}$ ) or aziridine (see $\mathbf{2}$ ) heteroatom for protonation by the acid-base residue in the binding pocket. In an acid-catalyzed nucleophilic attack, the epoxide/aziridine ring opens to form a covalent enzyme-inhibitor adduct. Compared to the acylal linkage featuring during $\beta$-glucose hydrolysis, the formed ester is considerably more stable, and the $\beta$-glucosidase is irreversibly disabled.

By virtue of their mechanism of action, cyclophellitol (1) and cyclophellitol-aziridine (2) are selective for retaining $\beta$-glucosidases over inverting $\beta$-glucosidases. This property distinguishes cyclophellitols from another class of glycosidase inhibitors: the iminosugars (amongst which the archetypal competitive glucosidase inhibitor is deoxynojirimycin). ${ }^{[7]}$ In recent years, covalent and irreversible inhibitors have received growing attention, as they are ideal starting points for the development of activitybased probes (ABPs). ${ }^{[8]}$ In the field of activity-based protein profiling (ABPP), covalent and irreversible inhibitors of an enzyme, or enzyme family, are equipped with a reporter entity - a fluo-

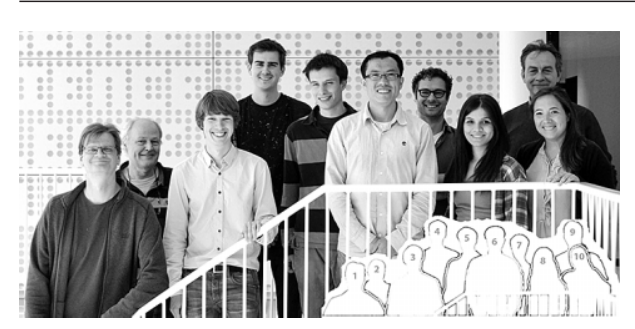

Jianbing Jiang (6) conducts his PhD research, funded by the China Scholarship Council, at Leiden University on the development of activity-based glycosidase probes. He will defend his Thesis in the Summer of this year. Thomas Beenakker (5), Sybrin Schröder (4) and Casper de Boer (3) pursue their PhD at Leiden University on chemical glycobiology subjects and plan to defend their Theses in the coming years. Rita Petracca (8) is a PhD student at the Istituto Italiano di Tecnologia Genoa, Italy, and in the course of a research exchange program studies the use of activity-based probes for target discovery and target engagement. Marta Artola (10) holds a PhD in organic chemistry from the Universidad Complutense de Madrid in Spain and performs post-doctoral research at Leiden University in the area of chemical glycobiology. Jeroen Codée (7), Gijs van der Marel (2) and Herman Overkleeft (1) have throughout their career at Leiden University pursued the design and synthesis of carbohydrates and carbohydrate mimetics, which they study for their biological activities in collaboration with Hans Aerts (9), formerly Academic Medical Centre, University of Amsterdam, currently at Leiden University. 


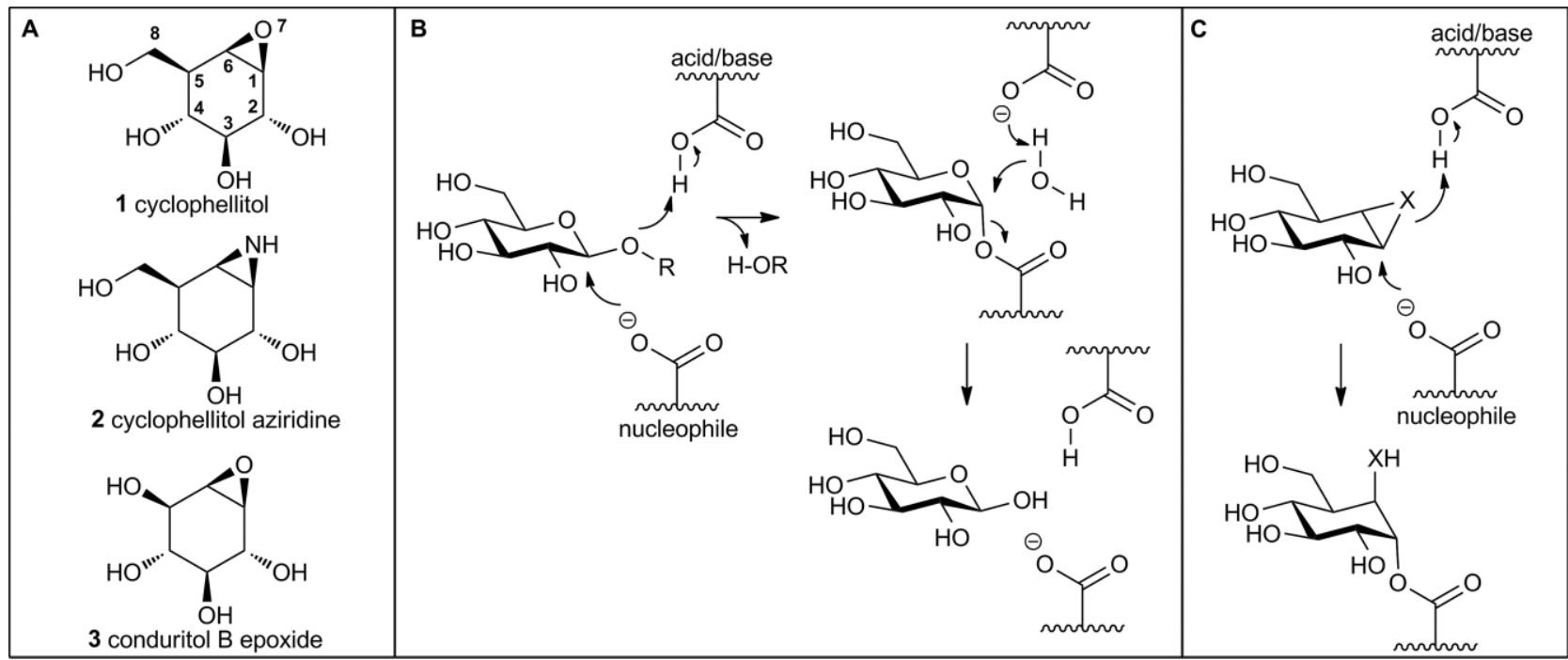

Figure 1. A) Structure of cyclophellitol (1), cyclophellitol-aziridine (2) and conduritol B epoxide (3). B) Mechanism employed by retaining $\beta$-glucosidases. C) Mechanism-based, irreversible retaining $\beta$-glucosidase inhibition by compounds $\mathbf{1}$ and $\mathbf{2}(\mathrm{X}=\mathrm{O}$ or $\mathrm{NH})$.

rophore, a biotin or a bioorthogonal tag - and used to profile their target enzymes in complex biological samples. Cyclophellitol (1) is on paper suited for this purpose, and has indeed been transformed ${ }^{[9]}$ into a highly selective ABP highly selective for the human retaining $\beta$-glucosidases.

Cyclophellitol-aziridine is the more attractive lead for ABP development. ${ }^{[10]}$ It is at least as potent an inhibitor as cyclophellitol, and the aziridine nitrogen can be modified with a range of functional groups, including reporter functionalities, without interfering with recognition by the target enzyme (at least, exo-glycosidases to which the target enzymes of $\mathbf{1}$ and $\mathbf{2}$ belong are often largely indiscriminate to the nature of the aglycon - the general space also occupied by an aziridine substituent). For this reason, as well as the finding that about half of the glycosidases known employ a Koshland double replacement mechanism, ${ }^{[11]}$ interest in cyclophellitol-aziridines has grown considerably in recent years. Their use as inhibitors and ABPs to monitor glycosidases recognizing and processing configurational and functional isosteres of glucose requires however effective synthetic routes to cyclophellitol-aziridines. Herein, we review the synthesis strategies reported to date, starting with the known syntheses of cyclophellitol-aziridine (2), followed by strategies towards configurational and functional analogues and overall with a focus on methodology towards cyclohexitol-aziridines mimicking pyranose sugars.

\section{Synthetic Strategies}

\subsection{Tatsuta's Synthesis of Cyclophellitol, Cyclophellitol Aziridine and Their 1,6-epi Isomers}

The group of Tatsuta was the first to study the synthesis of cyclophellitol derivatives. ${ }^{[12]}$ Closely following the discovery, by Umezawa, Takeuchi and colleagues, ${ }^{[1]}$ of cyclophellitol (1) and its annotation as a mechanism-based retaining $\beta$-glucosidase inhibitor, ${ }^{[13]}$ Tatsuta and co-workers disclosed the first synthesis of cyclophellitol (1) and cyclophellitol-aziridine (2), as well as their configurational analogues 1,6-epi-cyclophellitol (14, Scheme 1) and 1,6-epi-cyclophellitol-aziridine 12 (atom numbering as indicated in Figure 1, compound 1). As with most literature syntheses ${ }^{[14]}$ of cyclophellitol, the Tatsuta scheme ${ }^{[14]}$ starts from a chiral building block, here partially protected Didopyranose derivative 4 , which is prepared from L-glucose following established procedures. ${ }^{[15]}$ Swern oxidation and Wittig olefination on the primary alcohol is followed by hydrolysis of the methyl acetal. Subsequent reaction of the liberated hemiacetal with hydroxylamine provided oxime $\mathbf{5}$ in a series of standard transformations. In situ oxidation of the oxime in $\mathbf{5}$ to the corresponding nitrile oxide (treatment with sodium hypochlorite in dichloromethane) led to a [2+3] cycloaddition to give the key intermediate, isoxazoline $\mathbf{6}$ as the single stereoisomer. The isoxazoline $\mathrm{N}-\mathrm{O}$ bond was reduced by Raney nickel catalyzed hydrogenation, after which the free alcohols were protected as the diethylisopropylsilyl ethers to give cyclohexanone 7. Reduction of the carbonyl provided the desired alcohol in a 3:1 diastereomeric ratio, which was then transformed into mesylate $\mathbf{8}$. Catalytic hydrogenation followed by treatment with base led to removal of all protective groups. Finally, intramolecular $\mathrm{S}_{\mathrm{N}} 2$ substitution of the methanesulfonyl group yielded cyclophellitol (1). Perbenzylation of $\mathbf{1}$ followed by opening of the epoxide gave the mixture of trans-1,2-azido-alcohols 9 and 10. Treatment of this mixture with triphenylphosphine in a mixture of THF and water gave, after formation of the phosphazene and expulsion of triphenylphosphine oxide in a Staudinger type reaction, ${ }^{[16]}$ tetra-O-benzyl-1,6-epi-cyclophellitol-aziridine 11. Finally, removal of the benzyl groups under Birch conditions afforded 1,6-epi-cyclophellitol-aziridine 12.

In a similar fashion (though with altered conditions at various stages), Tatsuta and co-workers synthesized 1,6-epi-cyclophellitol $14^{[17]}$ starting from D-galactopyranose derivative 13 (a configurational isomer of $\mathrm{D}$-idose $\mathbf{4}$ with the same protective group pattern). The strategy to open the epoxide with sodium 


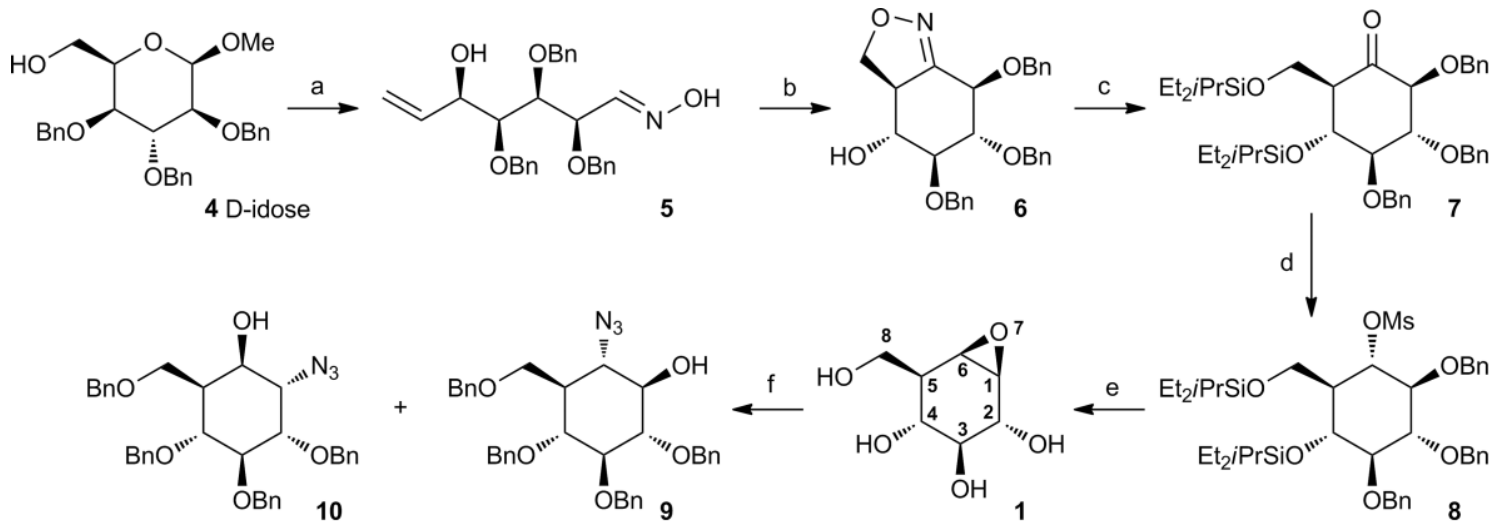

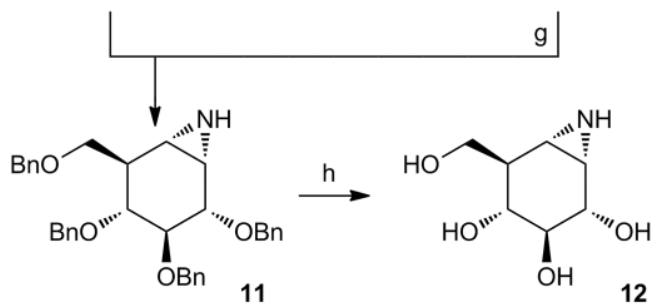

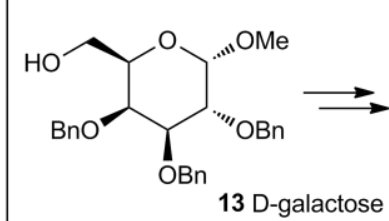<smiles>OC[C@@H]1[C@H]2O[C@H]2[C@@H](O)[C@H](O)[C@@H]1O</smiles><smiles>OC[C@H]1[C@@H](O)[C@@H](O)[C@@H](O)[C@@H]2N[C@H]12</smiles>

Scheme 1. Synthesis of cyclophellitol (1), 1,6-epi-cyclophellitol (14), cyclophellitol-aziridine (2) and 1,6-epi-cyclophellitol-aziridine (12) by Tatsuta and coworkers. Reagents and conditions: (a) i) $(\mathrm{COCl})_{2}, \mathrm{DMSO}^{\mathrm{Et}} \mathrm{E}_{3} \mathrm{~N},-78{ }^{\circ} \mathrm{C}$; ii) $\mathrm{Ph}_{3} \mathrm{P}=\mathrm{CH}_{2}$, benzene (75\%, two steps); iii) $\mathrm{HCl}$ (aq.), dioxane; iv) $\mathrm{HO}-\mathrm{NH}{ }_{2}$ ( $\mathrm{HCl}$ salt), pyridine ( $80 \%$, two steps); (b) $\mathrm{NaOCl}, \mathrm{CH}_{2} \mathrm{Cl}_{2}$ (70\%); (c) i) $\mathrm{H}_{2}$ (1 atm.), Raney $\mathrm{Ni}(80 \%)$; ii) diethylisopropyl triflate, $2,6-\mathrm{lutidine} \mathrm{CH}_{2} \mathrm{Cl}_{2}$; d) i) $\mathrm{BH}_{3} \cdot \mathrm{Me}_{2} \mathrm{~S}(45 \%$, three steps); e) i) $\mathrm{H}_{2}$ (1 atm.), $\mathrm{Pd}(\mathrm{OH})_{2}, \mathrm{MeOH}$; ii) $\mathrm{NaOH}$ (1 M, aq.) (75\%, two steps); (f) i) $\mathrm{NaH}, \mathrm{BnBr}, \mathrm{DMF}(90 \%)$; ii) $\mathrm{NaN}_{3}, \mathrm{DMF}^{\circ} 110{ }^{\circ} \mathrm{C}(27 \%$ 9, $41 \%$ 10); (g) i) $\mathrm{Ph}_{3} \mathrm{P}, \mathrm{THF} / \mathrm{H}_{2} \mathrm{O}$; ii) $\mathrm{NaOMe}, \mathrm{MeOH}\left(40 \%\right.$, two steps); h) $\mathrm{Li}, \mathrm{NH}_{3}$ (liq.), $\mathrm{THF},-78{ }^{\circ} \mathrm{C}(60 \%)$.

azide yielded a mixture of azido-alcohols, which were both transformed into the epimeric (with respect to the epoxide) aziridine using Staudinger conditions, proved to also be effective in the synthesis of cyclophellitol-aziridine 2 from 14 in comparable yields to that of the preparation of aziridine $\mathbf{1 2}$. The general strategy - installation of an aziridine in a two-step sequence (epoxide opening with nucleophilic azide followed by Staudinger reduction/cyclisation with inversion of configuration) - features in a number of subsequent syntheses as is described further on in this review.

\subsection{Synthesis of Cyclophellitol Aziridines 2 and 12: Ring- Closing Metathesis and Intramolecular lodo-Imination as the Key Steps}

The years following the pioneering synthesis studies of Tatsuta's group witnessed the rising impact of ring closing metathesis $(\mathrm{RCM})^{[18]}$ - the transformation of two terminal alkenes of an (acyclic) substrate into an internal alkene in a cyclic product in organic chemistry. Suitable transition metal catalysts became available ${ }^{[19]}$ capable to produce small to medium-sized rings from dienes featuring numerous functional groups. RCM evolved to become a key step in the synthesis of functionalized heterocycles ${ }^{[20]}$ and carbacycles, ${ }^{[21]}$ and is compatible with carbohydrate chemistry. ${ }^{[22]}$ This holds true as well for the synthesis of cyclophellitol/cyclophellitol-aziridine analogues, most of which are prepared nowadays through synthetic routes involving a RCM step.

Madsen and co-workers ${ }^{[23]}$ prepared cyclophellitol (1) via cyclohexene intermediate $\mathbf{2 0}$, itself prepared through RCM on the appropriate diene (Scheme 2). In this route (optimized by us recently $\left.{ }^{[24]}\right), \mathrm{D}$-xylose is converted in three steps into iodofuranoside 16. First, kinnetic Fischer glycosylation of D-xylose in methanol provided methyl xylofuranoside. Next the iodine was installed using conditions developed by Garegg and Samuelsson ${ }^{[25]}$ after which benzylation under acidic conditions of the two remaining secondary hydroxyls gave $\mathbf{1 6}$. Vasella fragmentation of $\mathbf{1 6}$ with zinc dust under sonication gave aldehyde $\mathbf{1 7}$. Indium-mediated Barbier reaction of $\mathbf{1 7}$ with ethyl 4-bromocrotonate yielded diene 19 in good yield and excellent stereochemistry - much better, as stated by the authors, ${ }^{[23]}$ than those found when performing the Barbier allylation with 4bromobut-2-en-1-ol instead of crotonate $\mathbf{6}$ (which, if successful, would have obviated the reduction of the methyl ester to the corresponding primary hydroxyl in a later stage). RCM of diene 19 with Grubbs second-generation ruthenium alkylidene catalyst ${ }^{[26]}$ and ensuing reduction of the methyl ester to the primary alcohol (treatment with DIBAL-H, followed by sodium borohydride reduction of the intermediate aldehyde) gave cyclohexene $\mathbf{2 0}$ in good yield. Madsen and colleagues continued their 


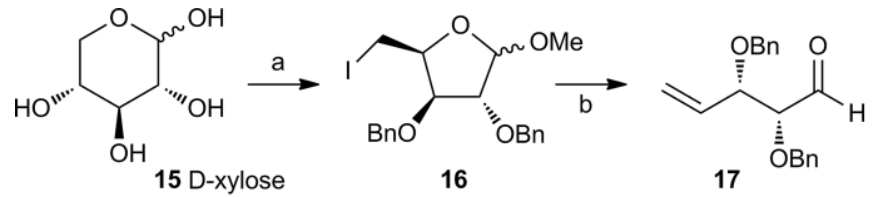

16

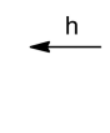<smiles>OC[C@H]1[C@@H](O)[C@@H](O)[C@H](O)[C@@H]2N[C@H]12</smiles><smiles>CC=CC(=O)OCC(C)(C)C</smiles><smiles>C=C[C@H](OCC)[C@@H](O)[C@@H](O)[C@H](C=C)C(=O)OCC</smiles>

19

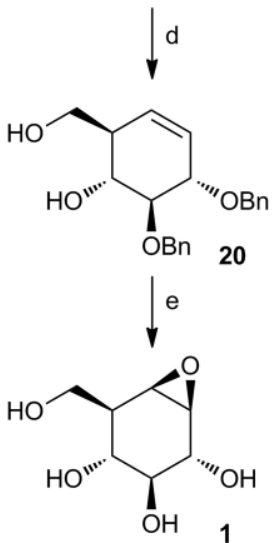

Scheme 2. Ring-closing metathesis as a key step in the synthesis of compounds 1 and 2. Reagents and conditions: (a) i) $\mathrm{HCl}_{1}, \mathrm{MeOH}^{\circ} 5^{\circ} \mathrm{C}$; ii) $\mathrm{I}_{2}, \mathrm{Ph}_{3} \mathrm{P}$, imidazole, THF (74 \%); iii) $\mathrm{BnOC}(=\mathrm{NH}) \mathrm{CCl}_{3}$, TfOH, dioxane (90\%); (b) $\mathrm{Zn}, \mathrm{THF} / \mathrm{H}_{2} \mathrm{O}$, ultrasound (78 \%); (c) indium powder, La(OTf) $)_{3}, \mathrm{H}_{2} \mathrm{O}$, ultrasound, $(80 \%)$; (d) i) secondgeneration Grubbs catalyst, $\mathrm{CH}_{2} \mathrm{Cl}_{2}, 40{ }^{\circ} \mathrm{C}\left(89 \%\right.$ ); ii) DIBAL-H, THF, $0{ }^{\circ} \mathrm{C}$ to room temp.; iii) $\mathrm{NaBH}_{4}, \mathrm{H}_{2} \mathrm{O}$, EtOAc (94 \%); (e) i) $m \mathrm{mPBA}, \mathrm{Na}_{2} \mathrm{HPO}_{4}$ (aq., $1 \mathrm{~m}$ ), $\mathrm{NaH}_{2} \mathrm{PO}_{4}$ (aq., $1 \mathrm{M}$ ), $\mathrm{DCE}, 50{ }^{\circ} \mathrm{C}(55 \%)$; ii) $\mathrm{H}_{2}, \mathrm{Pd}(\mathrm{OH})_{2}, \mathrm{MeOH}(88 \%)$; (f) $\mathrm{CCl}_{3} \mathrm{CN}, \mathrm{DBU}, \mathrm{CH}_{2} \mathrm{Cl}_{2}, 0^{\circ} \mathrm{C}$; (g) $\mathrm{I}_{2}, \mathrm{NaHCO}_{3}, \mathrm{H}_{2} \mathrm{O}$; (h) $\mathrm{HCl}\left(37 \%\right.$, aq.), dioxane, $60{ }^{\circ} \mathrm{C}$; (i) i) $\mathrm{NaHCO}$, $\mathrm{MeOH}\left(60 \%\right.$, four steps); ii) $\mathrm{Li}, \mathrm{NH}_{3}$ (liq.), $\mathrm{THF},-60{ }^{\circ} \mathrm{C}(70 \%)$.

synthesis to cyclophellitol (1) by capitalizing on the homoallylic alcohol in $\mathbf{2 0}$ for stereospecific introduction of the epoxide. Therefore, treatment of $\mathbf{2 0}$ with meta-chloroperbenzoic acid in dichloromethane followed by catalytic hydrogenation yielded cyclophellitol (1) in ten steps starting from D-xylose (15).

The homoallylic alcohol embedded in partially protected cyclohexene $\mathbf{2 0}$ proved also ideal for the stereospecific introduction of an amine functionality, as we demonstrated in our synthesis of cyclophellitol-aziridine (2). ${ }^{[2]}$ Reaction of $\mathbf{2 0}$ with trichloroacetonitrile and DBU as base gave trichloroacetimidate 21. lodocyclisation (with iodine and sodium hydrogen carbonate) followed by acidolysis of the resulting cyclic imidate $\mathbf{2 2}$, yielded stereospecifically trans-1-iodo-2-amine 23. Under mild basic conditions the iodine in $\mathbf{2 3}$ is displaced to form the aziridine - again in a stereospecific fashion - after which Birch reduction (lithium in liquid ammonia) gave cyclophellitol-aziridine in five steps from the Madsen cyclohexene $\mathbf{2 0 .}$

The accessible synthesis of cyclohexene $\mathbf{2 0}$, which can be performed to yield multi-gram quantities, combined with the control in stereochemical outcome exerted by the intramolecular iodo-imidation/iodine displacement sequence, led to the adaptation of the synthetic route of cyclophellitol-aziridine (2) (Scheme 2) towards 1,6-epi-cyclophellitol-aziridine (12). ${ }^{[27]}$ As outlined in Scheme 3, removal of the two benzyl ethers in $\mathbf{2 0}$ under Birch conditions was followed by selective installation of the benzylidene and selective transformation of the allylic alcohol (as opposed to the homo-allylic alcohol) into the trichloroacetimidate, yielding (labile) intermediate 24. Treatment of $\mathbf{2 4}$ with iodine now results in iodo-imination with delivery of the nitrogen at C1 from the "alpha" face (in terms of the parent Dglucopyranoside), as compared to C6-beta-delivery of the nitrogen seen in the transformation of $\mathbf{2 1}$ into $\mathbf{2 2}$ (Scheme 2). Following the same sequence of events, acidolysis of the cyclic imidate yielded trans-iodo-amine 25, which under mild basic conditions gave the desired 1,6-epi-cyclophellitol-aziridine 12.<smiles>C[13CH][C@H]1C=C[C@@H](CO)[C@@H](O)[C@H]1OBr</smiles><smiles>N=C(O[C@H]1C=C[C@@H]2COC(c3ccccc3)O[C@H]2[C@H]1O)C(Cl)(Cl)Cl</smiles><smiles>CC(C)[C@H]1[C@@H]2N[C@H]2[C@H](CO)[C@@H](O)[C@@H]1O</smiles>

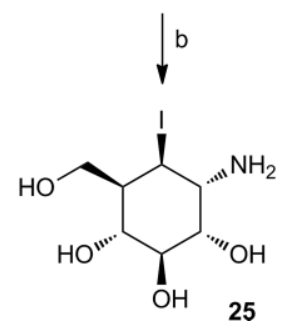

Scheme 3. Transformation of common intermediate 20 into 1,6-epi-cyclophellitol-aziridine 12. Reagents and conditions: (a) i) $\mathrm{Li}, \mathrm{NH}_{3}$ (liq.), $\mathrm{THF},-60{ }^{\circ} \mathrm{C}$ (57\%); ii) $\mathrm{PhCH}(\mathrm{OMe})_{2}, \mathrm{CSA}, \mathrm{DMF}(61 \%)$; iii) $\mathrm{CCl}_{3} \mathrm{CN}, \mathrm{DBU}, \mathrm{DCM}, 0{ }^{\circ} \mathrm{C}$; (b) i) $\mathrm{NaHCO}_{3}, \mathrm{I}_{2}, \mathrm{H}_{2} \mathrm{O}$ (41\%, two steps); ii) $\mathrm{HCl}\left(37 \%\right.$, aq.), dioxane; (c) $\mathrm{NaHCO}_{3}$, $\mathrm{MeOH}$ (63\%, two steps).

\subsection{Synthesis of Configurational and Functional Cyclophellitol Aziridine Isomers: lodo-Imination/ Substitution vs. Epoxide Opening/Staudinger Cyclisation}

In recent years syntheses of a number of cyclophellitol-aziridines differing in configuration and/or substitution pattern from the glucopyranose configured compounds 1 and 14 have appeared in the literature. These syntheses share a number of features with the strategies outlined above. They all use chiral pool building blocks as starting material, RCM may feature as a key step and the aziridine moiety is introduced from either an 
epoxide precursor (with full stereocontrol and retention of configuration - stereocontrol in epoxide formation is not always complete though) or through intramolecular iodocyclisation from a partially protected (homo)-allylic alcohol precursor.

The synthesis of 4-epi-cyclophellitol-aziridine $\mathbf{3 1}$ (a configurational analogue of $\beta$-galactopyranose) and 1,4,6-epi-cyclophellitol-aziridine 34 (a configurational analogue of $\alpha$-galactopyranose) starts with a dibutylboryl triflate-catalyzed stereoselective aldol condensation of aldehyde $\mathbf{1 7}$ and Evans' oxazolidinone 26, in a procedure developed by Llebaria and co-workers. ${ }^{[28]}$ Reduction of the amide in $\mathbf{2 7}$ to the primary alcohol (with concomitant removal of the chiral Evans' auxiliary) followed by RCM yielded partially protected cyclohexene $\mathbf{2 8}$, which can be regarded as the galactopyranose equivalent of common building block $\mathbf{2 0}$ that was used to synthesize both cyclophellitol-aziridine 2 (Scheme 2) and 1,6-epi-cyclophellitolaziridine (12) (Scheme 1). Following the synthetic schemes as outlined for compounds $\mathbf{2}$ and $\mathbf{1 2}$ indeed yielded 5-epi-cyclophellitol-aziridine (31) and 1,2,5-epi-cyclophellitol (34). ${ }^{[29]}$ The synthesis of compound $\mathbf{3 1}$ proceeded with an efficiency equal to that observed in the synthesis of cyclophellitol-aziridine (2) and with absolute stereocontrol as offered by the intramolecular iodo-imination/intramolecular substitution protocol. The synthesis of compound $\mathbf{3 4}$ required the preparation of 4-epicyclophellitol 29, which was accomplished after perbenzylation of $\mathbf{2 8}$ followed by epoxidation with $m C$ PBA, which proceeded with remarkable stereoselectivity given that no (homo)-allylic alcohol is present in the precursor to guide the epoxidation. In their original publication ${ }^{[28]}$ on the synthesis of $\mathbf{2 8}$, Llebaria and co-workers produced the perbenzylated, galacto-configured cyclophellitol $\mathbf{2 9}$ through stereoselective dihydroxylation of cyclohexene $\mathbf{2 8}$ followed by reaction with excess of the MattocksMoffat reagent, 2-acetoxyisobutyryl bromide. ${ }^{[30]}$ The resulting crude mixture of trans-cyclohexane bromoacetates was treated with potassium carbonate to give compound 29 in good yield as well.

One attractive feature of chiral pool material in synthesis is that - providing that the enantiomer is available and affordable

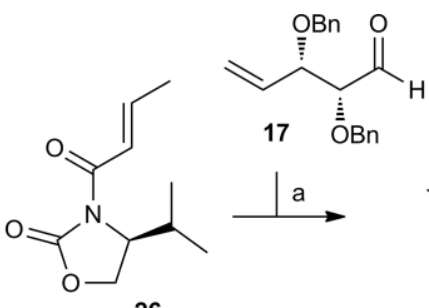

26

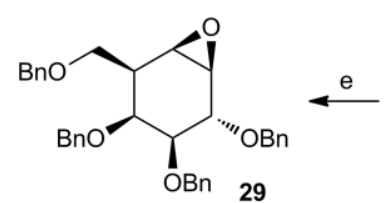<smiles>OC[C@H]1C=C[C@H](Br)[C@H](O)[C@@H]1OCc1ccccc1</smiles><smiles>C=C(C[12CH3])C[123I]</smiles><smiles>N[C@H]1[C@@H](O)[C@H](COCc2ccccc2)[C@@H](O[C@H](Cc2ccccc2)c2ccccc2)[C@H](O)[C@@H]1O</smiles><smiles>[131In]</smiles>
33

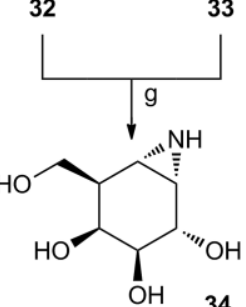<smiles>C=CC(C(=O)N1C(=O)OCC1C(C)C)C(O)C(O)C(O)C(=O)c1ccccc1</smiles>

27<smiles>C=CC(C(=O)O)[C@H](O)[C@H](O)[C@H](C=C)C(=O)N1C(=O)OC[C@H]1C(C)C</smiles>

35

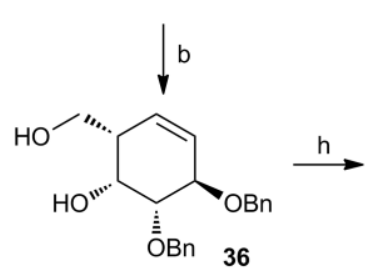<smiles>C[C@H]1C=C[C@@H](OCc2ccccc2)[C@H](O)[C@@H]1O</smiles><smiles>C[C@@H]1C=C[C@@H](OC(=N)C(Cl)(Cl)Cl)[C@H]2OC(C)(C)O[C@H]12</smiles><smiles>C[C@H]1[C@H](O)[C@@H](O)[C@H](O)[C@H]2N[C@@H]21</smiles>

Scheme 4. Synthesis of galactose and fucose-configured cyclophellitol-aziridines. Reagents and conditions: (a) $\mathrm{Bu}_{2} \mathrm{BSO}_{3} \mathrm{CF}_{3}, \mathrm{Et}_{3} \mathrm{~N}_{1} \mathrm{CH}_{2} \mathrm{Cl}_{2},-78{ }^{\circ} \mathrm{C}$ to $-20{ }^{\circ} \mathrm{C}$ (80\%); (b) i) $\mathrm{LiBH}_{4}, \mathrm{THF} / \mathrm{H}_{2} \mathrm{O}, 0{ }^{\circ} \mathrm{C}$ to room temp. (85\%); ii) second-generation Grubbs catalyst, $\mathrm{CH}_{2} \mathrm{Cl}_{2}, 40{ }^{\circ} \mathrm{C}(78 \%)$; (c) $\mathrm{CCl}_{3} \mathrm{CN}, \mathrm{DBU}, \mathrm{CH}_{2} \mathrm{Cl}_{2}, 0{ }^{\circ} \mathrm{C}$; (d) i) $\mathrm{I}_{2}$, $\mathrm{NaHCO}_{3}, \mathrm{H}_{2} \mathrm{O}$; ii) $\mathrm{HCl}\left(37 \%\right.$ aq.), $\mathrm{MeOH}$, iii) $\mathrm{HCl}\left(37 \%\right.$ aq.), dioxane, $60{ }^{\circ} \mathrm{C}$; iv) $\mathrm{NaHCO}_{3}, \mathrm{MeOH}\left(60 \%\right.$, four steps), (d) $\mathrm{Li}, \mathrm{NH}{ }_{3}$ (liq.), $\mathrm{THF},-60{ }^{\circ} \mathrm{C}$; (e) i) $\mathrm{NaH}, \mathrm{BnBr}$, TBAl, DMF (85 \%); ii) $m$ CPBA, $\mathrm{CH}_{2} \mathrm{Cl}_{2}$ (63\%); (f) $\mathrm{NaN}_{3}, \mathrm{LiClO}_{4}, \mathrm{MeCN}, 80^{\circ} \mathrm{C}(73 \%, 32: 331: 1.3)$; (g) i) $\mathrm{Ph}_{3} \mathrm{P}, \mathrm{MeCN}^{\circ} 80{ }^{\circ} \mathrm{C}(26 \%)$; ii) $\mathrm{Li}, \mathrm{NH}{ }_{3}, \mathrm{THF}^{\circ}-60{ }^{\circ} \mathrm{C}$; (h) i) $\mathrm{TsCl}$, $\mathrm{Et}_{3} \mathrm{~N}, \mathrm{CH}_{2} \mathrm{Cl}_{2}(87 \%)$; ii) $\mathrm{LiAlH}_{4}, \mathrm{THF}, 0{ }^{\circ} \mathrm{C}$ to room temp. (87\%); (i) i) $\mathrm{Li}, \mathrm{NH}_{3}$ (liq.), $\mathrm{THF},-60{ }^{\circ} \mathrm{C}$ (73 \%); ii) 2,2-dimethoxypropane, $\mathrm{CSA}$ (60 \%); iii) $\mathrm{CCl} 3 \mathrm{CN}, \mathrm{DBU}$, $\mathrm{CH}_{2} \mathrm{Cl}_{2}$; (j) i) $\mathrm{CCl}_{3} \mathrm{CN}, \mathrm{DBU}, \mathrm{CH}_{2} \mathrm{Cl}_{2}$; ii) $\mathrm{NaHCO}_{3}, \mathrm{I}_{2}, \mathrm{H}_{2} \mathrm{O}$ (46 \%); iii) $\mathrm{HCl}$ (37\% aq.), $\mathrm{MeOH}, 60{ }^{\circ} \mathrm{C}$; iv) $\mathrm{NaHCO}, \mathrm{MeOH}$, room temp. (65 \%, four steps). 


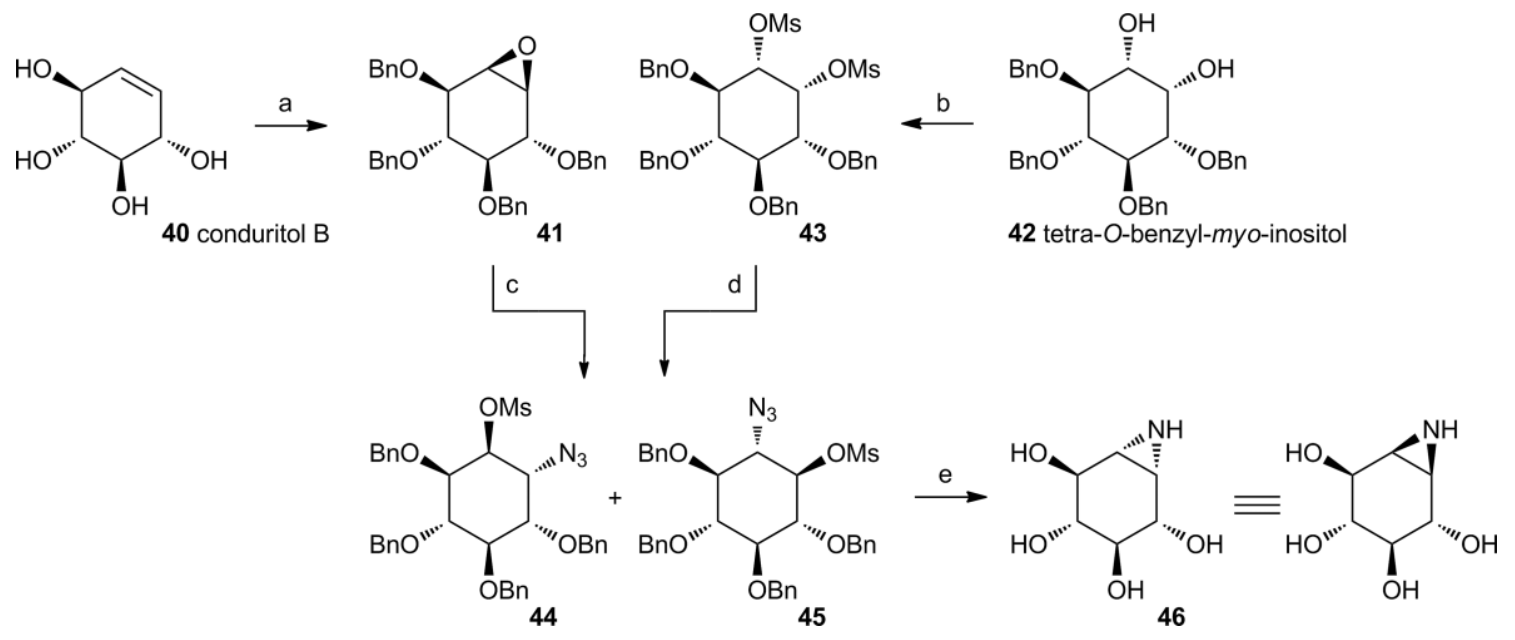

Scheme 5. Syntheses of conduritol B aziridine. Reagents and conditions: (a) i) $m\left(\mathrm{CBA}, \mathrm{CH}_{2} \mathrm{Cl}_{2}\right.$; ii) $\mathrm{NaH}, \mathrm{BnBr}$ (on racemic conduritol, for enantiopure $\mathbf{4 0}$ see ${ }^{[33]}$ );

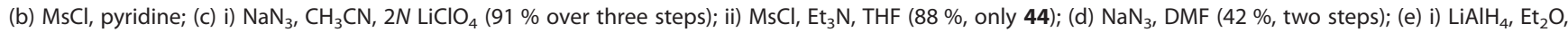
$0{ }^{\circ} \mathrm{C}(60 \%)$; ii) $\mathrm{Na}, \mathrm{NH}_{3}, \mathrm{THF},-78{ }^{\circ} \mathrm{C}(86 \%) .{ }^{[34]}$

- subjecting this enantiomer to the same sequence of events will yield the mirror image products. Both aldehyde 17 and oxazolidinone $\mathbf{2 6}$ are readily available in enantiomeric form and their condensation following the Mukayama-aldol procedure developed by Llebaria and co-workers ${ }^{[26]}$ gave access to diene $\mathbf{3 5}$, being the mirror image of 27. Processing $\mathbf{3 5}$ similar to $\mathbf{2 7}$ would yield a set of L-galactose-configured cyclophellitol-aziridines. The 6-deoxy analogue of L-galactose, L-fucose is often encountered - $\alpha$-linked - in naturally occurring glycoconjugates. With the aim to develop covalent and irreversible $\alpha$ fucosidase inhibitors, we synthesized 8-deoxy-2,3,5-epi-cyclophellitol-aziridine (39) following a route related to the one depicted in Scheme $3 .^{[31]}$ Following RCM (35 to 36 ), the primary alcohol was reduced to the methyl group (36 to 37 ) after which the debenzylation, protection of the cis-diol and reaction of the remaining allylic alcohol with trichloroacetonitrile yielded imidate 38. lodo-imination, acidolysis and base-catalyzed intramolecular iodide substitution provided aziridine (39) - a configurational analogue of $\alpha$-L-fucopyranose. The above schemes represent all configurational and functional cyclophellitol-aziridines (namely, 1, 12, 31, 32, and 39) whose synthesis has been reported to date. Studies on the synthesis of related compounds exists, however, both targeting cyclopentitol-aziridines ${ }^{[32]}$ (not shown here) and in particular conduritol-aziridines (Scheme 4).

Scheme 5 depicts two recent and representative syntheses of the broad-spectrum retaining glucosidase inhibitor, conduritol $B$ aziridine (46) (both $\alpha$ - and $\beta$-glucosidase). ${ }^{[35]}$ In the first route, ${ }^{[36]}$ the natural product, conduritol $B(\mathbf{4 0})$ is perbenzylated followed by epoxidation to afford fully protected conduritol B epoxide 41. Opening of the epoxide with azide, mesylation of the resulting secondary hydroxyl, Staudinger ring-closure and final debenzylation provided conduritol B aziridine (46). In an alternative route, the mixture of azides $\mathbf{4 4}$ and $\mathbf{4 5}$ was prepared from another natural product, myo-inositol $(\mathbf{4 2})^{[37]}$ protected as the tetra-O-benzyl derivative, via a number of standard protective group and functional group manipulations.

\section{Discussion}

Cyclitol epoxides were widely used in the sixties of the past century as mechanism-based, irreversible glycosidase inhibitors. Conduritol $B$ epoxide (CBE), discovered and exploited by Legler and co-workers, ${ }^{[4]}$ was the glucosidase inhibitor of choice up until the discovery in 1967 of the polyhydroxylated alkaloid, deoxynojirimycin. ${ }^{[7]}$ In the following decades, cyclitol epoxides and cyclitol-aziridines received relatively little attention. In 1989, the Withers group ${ }^{[35]}$ proposed that a CBE homologue bearing an extra methylene would fit better within a glucosidase active site and suggested that such a compound should be synthesized. Shortly thereafter, cyclophellitol (1) was discovered ${ }^{[1]}$ as a natural product and shown to be a potent and highly selective inhibitor of retaining $\beta$-glycosidases. These discoveries led to some renewed interest in the cyclitol epoxide/aziridine compound class, and several studies on the synthesis of $\mathbf{1}$ and evaluation as enzyme inhibitors and its functional and configurational analogues were reported.

In recent years, and in conjunction with a general rise in interest in covalent, irreversible inhibitors as starting point for the development of ABPP methodology, ${ }_{1}^{[7]}$ cyclophellitol (1), cyclophellitol-aziridine (2) and analogous structures are receiving renewed attention.

To date, ABPs have been reported that enable selective profiling of retaining glycosidases such as $\beta$-glucosidases, ${ }^{[38]} \alpha$ glucosidases, ${ }^{[27]} \alpha$-galactosidases ${ }^{[29 b]}$ and $\alpha$-fucosidases, ${ }^{[31]}$ which are designed based on compound $\mathbf{2}$ bearing $\mathrm{N}$-substituents featuring a fluorophore or biotin as a reporter entity. Cyclophellitol-aziridine (2) has proven to be a superior scaffold compared to 2 (or 5)-deoxy-5-fluoroglycosides ${ }^{[39]}$ for in vitro and in situ ABPP of retaining $\beta$-glucosidase activities ${ }^{[40]}$ and adaptation of the configuration and substitution pattern will likely yield selective ABPs for retaining glycosidase families evolved to recognize and hydrolyze the underlying configurational carbohydrates - next to monosaccharides (exoglycosidases ${ }^{[41]}$ ) likely also oligosaccharides (endoglycosidases ${ }^{[42]}$ ). To fulfil this 


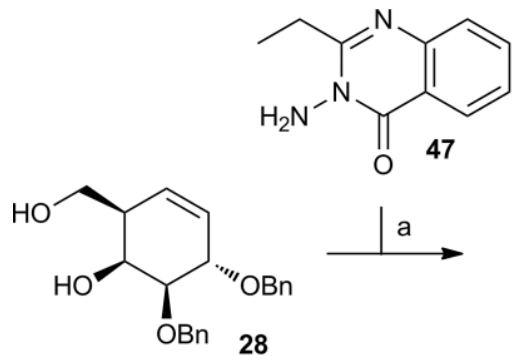<smiles>CCc1nc2ccccc2c(=O)n1N1[C@@H]2[C@H](Cc3ccccc3)[C@@H](O)[C@H](O)[C@@H](CO)[C@H]21</smiles>

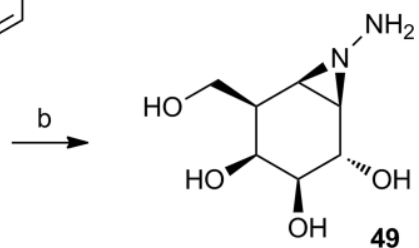

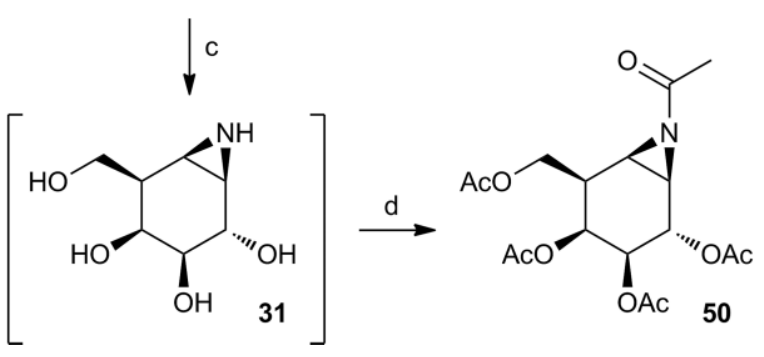

Scheme 6. Direct aziridination of protected cyclohexene 28. Reagents and conditions: (a) $\mathrm{Phl}(\mathrm{OAc})_{2}, \mathrm{~K}_{2} \mathrm{CO}_{3}, \mathrm{CH}_{2} \mathrm{Cl}_{2}(54 \%)$; (b) i) $\mathrm{H}_{2} \mathrm{~N}-\mathrm{NH}_{2}, 120{ }^{\circ} \mathrm{C}(78 \%$ ); ii) $\mathrm{Na}$, $\mathrm{NH}_{3}$ (liq.), $\mathrm{THF},-78{ }^{\circ} \mathrm{C}(91 \%)$; (c) i) $\mathrm{Na}, \mathrm{NH}_{3}$ (liq.), $\mathrm{THF},-78{ }^{\circ} \mathrm{C}$; ii) $\mathrm{Ac}_{2} \mathrm{O}$, pyridine ( $28 \%$, two steps).

promise, though, synthetic methodology needs to be expanded to enable easy access to an array of configurational and functional cyclophellitol/cyclophellitol-aziridine analogues. The aziridine moiety in all the syntheses described in this review is installed either by modification of an epoxide precursor or through iodocyclization starting from a (homo)allylic alcohol precursor. Expansion of methodology that enables the introduction of an aziridine ${ }^{[43]}$ at various stages of the synthesis is important to access to a wide array of cyclophellitol-aziridine analogues. Llebaria and co-workers recently reported ${ }^{[44]}$ direct aziridination of galacto-configured cyclohexene $\mathbf{2 8}$ (Scheme 6). Although the objective of this synthetic study was to obtain $\mathrm{N}$ amino-aziridine 49, the authors showed that reduction of the $\mathrm{N}-\mathrm{N}$ bond yields 5-epi-cyclophellitol-aziridine (31) (the structure of which was established after peracetylation to 50). Direct aziridination - either by reaction with aminoquinazolinones ${ }^{[44]}$ or by means of other recently published ${ }^{[45]}$ methodology - will likely evolve to become a complementary method for the synthesis of cyclophellitol-aziridine analogues, thus expanding the chemical toolbox of covalent, irreversible glycosidase inhibitors and activity-based glycosidase probes derived thereof.

\section{Acknowledgments}

The authors thank the China Scholarship Council (CSC) for a PhD grant to J. B. J.), the Netherlands Organization for Scientific Research (NWO) for a ChemThem grant to J. M. A. and H. S. O. and the European Research Council (ERC) (ErC-2011-AdG290836, grant to H. S. O.) for financial support.

Keywords: Inhibitors · Enzyme inhibitors - Retaining glycosidases - Small-ring systems - Nitrogen heterocycles . Cyclophellitol

[1] S. Atsumi, K. Umezawa, H. linuma, H. Naganawa, H. Nakamura, Y. litaka, T. Takeuchi, J. Antibiot. 1990, 43, 49-53.
[2] S. Tatsuta, Y. Niwata, K. Umezawa, K. Toshima, M. Nakata, J. Antibiot. 1991, 44, 912-914.

[3] D. Koshland, Biol. Rev. 1953, 28, 416-436.

[4] a) G. Legler, Hoppe-Seyler's Z. Physiol. Chem. 1966, 345, 197-214; b) G. Legler, Hoppe-Seyler's Z. Physiol. Chem. 1968, 349, 767-774.

[5] G. J. Davies, A. Planas, C. Rovira, Acc. Chem. Res. 2012, 45, 308-316.

[6] For some reviews on the mechanism of glycosyl hydrolases, see: a) D. J. Vocadlo, G. J. Davies, Curr. Opin. Chem. Biol. 2008, 12, 539-555; b) G. Davies, B. Henrissat, Structure 1995, 15, 853-859.

[7] a) H. Paulsen, Angew. Chem. Int. Ed. Engl. 1966, 5, 495-510; Angew. Chem. 1966, 78, 501; b) M. Yagi, T. Koumo, Y. Aoyagi, H. Murai, Nippon Nogei Kagaku Kaishi 1976, 50, 571-572; c) Iminosugars as glycosidase inhibitors: nojirimycin and beyond (Ed.: A. E. Stütz), Wiley-VCH, Weinheim, Germany, 1999.

[8] a) Y. Liu, M. P. Patricelli, B. F. Cravatt, Proc. Natl. Acad. Sci. USA 1999, 96, 14694-14699; b) D. Greenbaum, K. F. Medzihradsky, A. Burlingame, M. Bogyo, Chem. Biol. 2000, 7, 569-581; c) A. Borodovsky, B. M. Kessler, R. Casagrande, H. S. Overkleeft, K. D. Wilkinson, H. L. Ploegh, EMBO J. 2001, 20, 5187-5196.

[9] M. D. Witte, W. W. Kallemeijn, J. Aten, K.-Y. Li, A. Strijland, W. E. DonkerKoopman, B. Blijlevens, G. Kramer, A. M. C. H. van den Nieuwendijk, B. I. Florea, B. Hooibrink, C. E. M. Hollak, R. Ottenhoff, R. G. Boot, G. A. van der Marel, H. S. Overkleeft, J. M. F. G. Aerts, Nat. Chem. Biol. 2010, 6, 907-913.

[10] L. I. Willems, J. Jiang, K.-Y. Li, M. D. Witte, W. W. Kallemeijn, T. J. N. Beenakker, S. P. Schröder, J. M. F. G. Aerts, G. A. van der Marel, J. D. C. Codée, H. S. Overkleeft, Chem. Eur. J. 2014, 20, 10864-10872.

[11] a) For the CAZypedia website on carbohydrate-active enzymes, see: http://www.cazypedia.org/index.php/Glycoside_hydrolases; b) for a description of the CAZypedia website, see: V. Lombard, H. Golaconda Ramulu, E. Drula, P. M. Coutinho, B. Henrissat, Nucleic Acids Res. 2014, 42, D490-495.

[12] K. Tatsuta, Y. Niwata, K. Umezawa, K. Toshima, M. Nakata, Tetrahedron Lett. 1990, 31, 1171-1172.

[13] K. Tatsuta, Y. Niwata, K. Umezawa, K. Toshima, M. Nakata, J. Antibiot. 1991, 44, 456-458.

[14] a) K. Tatsuta, Y. Niwata, K. Umezawa, K. Toshima, M. Nakata, Carbohydr. Res. 1991, 222, 189-203; b) for a review on cyclophellitol synthesis, see: J. Marco-Contelles, Eur. J. Org. Chem. 2001, 1607-1618.

[15] a) D. Semeria, M. Philippe, J.-M. Delaumeny, A.-M. Sepulchre, S. D. Gero, Synthesis 1983, 710-713; b) A. Lipták, I. Jodal, P. Násáni, Carbohydr. Res. 1975, 44, 1-11. 
[16] a) P. Pöchlauer, E. P. Müller, Helv. Chim. Acta 1984, 67, 1238-1247; b) B. Ritzen, M. C. M. van Oers, F. L. van Delft, F. P. J. T. Rutjes, J. Org. Chem. 2009, 74, 7548-7551.

[17] a) For a review of the Tatsuta laboratory on the synthesis of cyclophellitols, see: K. Tsatuta, Pure Appl. Chem. 1996, 68, 1341-1446; b) see also ref. 2 and 13.

[18] a) R. R. Schrock, J. S. Murdzek, G. C. Bazan, J. Robbins, M. DiMare, M. O'Regan, J. Am. Chem. Soc. 1990, 112, 3875-3886; b) G. C. Fu, R. H. Grubbs, J. Am. Chem. Soc. 1992, 114, 7324-7325.

[19] a) S. Nguyen, R. H. Grubbs, J. Am. Chem. Soc. 1993, 115, 3800-3801; b) P. Schwab, R. H. Grubbs, J. W. Ziller, J. Am. Chem. Soc. 1996, 118, 100110.

[20] For an example, see: a) M. F. Schneider, H. Junga, S. Blechert, Tetrahedron 1995, 51, 13003-13014; b) H. S. Overkleeft, U. K. Pandit, Tetrahedron Lett. 1996, 37, 547-550; c) for a review, see: R. H. Grubbs, S. Chang, Tetrahedron 1998, 54, 4413-4450.

[21] For an example, see: a) H. Ovaa, J. D. C. Codée, B. Lastdrager, H. S. Overkleeft, G. A. van der Marel, J. H. van Boom, Tetrahedron Lett. 1999, 40, 5063-5066; b) P. Kapferer, F. Sarabia, A. Vasella, Helv. Chim. Acta 1999, $82,645-656$

[22] M. Jorgensen, P. Hadwiger, R. Madsen, A. E. Stütz, T. M. Wrodnigg, Curr. Org. Chem. 2000, 4, 565-588.

[23] F. G. Hansen, E. Bundgaard, R. Madsen, J. Org. Chem. 2005, 70, 1013910142

[24] K.-Y. Li, J. Jiang, M. D. Witte, W. W. Kallemeijn, H. van den Elst, C.-S. Wong, S. D. Chander, S. Hoogendoorn, T. J. M. Beenakker, J. D. C. Codée, J. M. F. G. Aerts, G. A. van der Marel, H. S. Overkleeft, Eur. J. Org. Chem. 2014, 6030-6043.

[25] P. J. Garegg, B. Samuelsson, J. Chem. Soc. Perkin Trans. 1 1980, 1, 28662869.

[26] M. Scholl, S. Ding, C. W. Lee, R. H. Grubbs, Org. Lett. 1999, 1, 953-956.

[27] J. Jiang, C.-L. Kuo, L. Wu, C. Franke, W. W. Kallemeijn, B. I. Florea, E. van Meel, G. A. van der Marel, J. D. C. Codée, R. G. Boot, G. J. Davies, H. S. Overkleeft, J. M. F. G. Aerts, ACS Central Sci. 2016, DOI: 10.1021/ acscentsci.6b00057.

[28] Y. Harrak, C. M. Barra, A. Delgado, A. R. Castano, A. Llebaria, J. Am. Chem. Soc. 2011, 133, 12079-12084.

[29] a) L. I. Willems, T. J. M. Beenakker, B. Murray, B. Gadestein, H. van den Elst, E. R. van Rijssel, J. D. C. Codée, W. W. Kallemeijn, J. M. F. G. Aerts, G. A. van der Marel, H. S. Overkleeft, Eur. J. Org. Chem. 2014, 6044-6056; b) L. I. Willems, T. J. M. Beenakker, B. Murray, S. Scheij, W. W. Kallemeijn, R. G. Boot, M. Verhoek, W. E. Donker-Koopman, M. J. Ferraz, E. R. van Rijssel, B. I. Florea, J. D. C. Codée, G. A. van der Marel, J. M. F. G. Aerts, H. S. Overkleeft, J. Am. Chem. Soc. 2014, 136, 11622-11625.

[30] a) A. R. Mattocks, J. Chem. Soc. 1964, 4840-4845; b) A. F. Russell, S. Greenberg, J. G. Moffatt, J. Am. Chem. Soc. 1973, 95, 4025-4030.

[31] J. B. Jiang, W. W. Kallemeijn, D. W. Wright, A. M. C. H. van den Nieuwendijk, V. C. Rohde, E. C. Folch, H. van den Elst, B. I. Florea, S. Scheij, W. E. Donker-Koopman, M. Verhoek, N. Li, M. Schurmann, D. Mink, R. G. Boot, J. D. C. Codée, G. A. van der Marel, G. J. Davies, J. M. F. G. Aerts, H. S. Overkleeft, Chem. Sci. 2015, 6, 2782-2789.

[32] O. L. Lopez, J. G. Fernandez-Bolanos, V. H. Lillelund, M. Bols, Org. Biomol. Chem. 2003, 1, 478-482.
[33] a) C. Jaramillo, J.-L. Chiara, M. Martín-Lomas, J. Org. Chem. 1994, 59, 3135-3141; b) P. Serrano, A. Llebaria, A. Delgado, J. Org. Chem. 2002, 67, 7165-7167.

[34] Though the final Birch reduction is not described in the referenced paper, this procedure does yield aziridine $\mathbf{4 4}$ as we have found (not published) in the stated yield. Alternatively, compound $\mathbf{4 3}$ features also as an intermediate in the first synthesis of $\mathbf{4 4}$ (see ref. $\mathbf{3 3}$ ), where it is stated that $\mathbf{4 4}$ can be produced from $\mathbf{4 3}$ by catalytic hydrogenation.

[35] G. Caron, S. G. Withers, Biochem. Biophys. Res. Commun. 1989, 163, 495499.

[36] P. Serrano, A. Llebaria, A. Delgado, J. Org. Chem. 2005, 70, 7829-7840.

[37] B. T. Adams, S. Niccoli, M. A. Chowdhury, A. N. K. Esarik, S. J. Lees, B. P. Rempel, C. P. Phenix, Chem. Commun. 2015, 51, 11390-11393.

[38] W. W. Kallemeijn, K. Y. Li, M. D. Witte, A. R. Marques, J. Aten, S. Scheij, J. Jiang, L. I. Willems, T. M. Voorn-Brouwer, C. P. van Roomen, R. Ottenhoff, R. G. Boot, H. van den Elst, M. T. Walvoort, B. I. Florea, J. D. Codee, G. A. van der Marel, J. M. Aerts, H. S. Overkleeft, Angew. Chem. Int. Ed. 2012, 51, 12529-12533; Angew. Chem. 2012, 124, 12697.

[39] a) S. G. Withers, I. P. Street, P. Bird, D. H. Dolphin, J. Am. Chem. Soc. 1987, 109, 7530-7531; b) S. G. Withers, K. Rupitz, I. P. Street, J. Biol. Chem. 1988, 263, 7929-7932; c) for a review on mechanism-based glycosidase inhibitors, including fluoroglycosides, see: B. P. Rempel, S. G. Withers, Glycobiology 2008, 18, 570-586.

[40] a) M. T. C. Walvoort, W. W. Kallemeijn, L. I. Willems, M. D. Witte, J. M. F. G. Aerts, G. A. van der Marel, J. D. C. Codée, H. S. Overkleeft, Chem. Commun. 2012, 48, 10386-10388; for studies on the use of fluoroglysosides in activity-based glycosidase profiling studies, see: b) D. J. Vocadlo, C. R. Bertozzi, Angew. Chem. Int. Ed. 2004, 43, 5338-5342; Angew. Chem. 2004, 116,$5452 ;$ c) O. Hekmat, Y.-W. Kim, S. J. Williams, S. He, S. G. Withers, J. Biol. Chem. 2005, 280, 35126-35135; d) K. A. Stubbs, A. Scaffidi, A. W. Debowski, B. L. Mark, R. V. Stick, D. J. Vocadlo, J. Am. Chem. Soc. 2008, 130, 327-335.

[41] For an example of a 6-phospho-cyclophellitol-sensitive enzyme that would be amenable for 6-phosphocyclophellitol-aziridine-based ABPP experiments, see: D. H. Kwan, Y. Jin, J. Jiang, H. M. Chen, M. P. Kötzler, H. S. Overkleeft, G. Davies, S. G. Withers, FEBS Lett. 2016, 590, 461-468.

[42] For an example of a glucosyl 1,6-epi-cyclophellitol-sensitive endoglucosidase that would be amenable for glucosyl 1,6-epi-cyclophellitolaziridine-based ABPP experiments, see: S. Caner, X. Zhang, J. Jiang, H.M. Chen, N. T. Nguyen, H. Overkleeft, G. D. Brayer, S. G. Withers, FEBS Lett. 2016, 590, 1143-1151.

[43] For recent reviews on aziridine synthesis, see: a) $\mathrm{H}$. Pellissier, Tetrahedron 2010, 66, 1509-1555; b) L. Degennaro, P. Trinchera, R. Luisi, Chem. Rev. 2014, 114, 7881-7929.

[44] A. Alcaide, A. Trapero, Y. Pérez, A. Llebaria, Org. Biomol. Chem. 2015, 13, 5690-5697.

[45] a) J. L. Jat, M. P. Paudyal, H. Gao, Q.-L. Xu, M. Youssufuddin, D. Devarajan, D. H. Ess, L. Kürti, J. R. Falck, Science 2014, 343, 61-65; b) S. O. Scholz, E. P. Farney, S. Kim, D. M. Bates, T. P. Yoon, Angew. Chem. Int. Ed. 2016, 55, 2239-2242; Angew. Chem. 2016, 128, 2279-2282.

Received: April 14, 2016

Published Online: May 25, 2016 